\title{
Development and Evaluation of Clostridium perfringens Type D Toxoid Vaccines
}

\author{
Mumtaz Ali Khan', Aneela Zameer Durrani', Sher Bahadar Khan², \\ Shehla Gul Bokhari', Ikramul Haq,*, Imdad Ullah Khan ${ }^{3}$, Naimat Ullah ${ }^{4}$, \\ Naimat Ullah Khan ${ }^{4}$, Kashif Hussain ${ }^{1}$ and Azmat Ullah Khan ${ }^{2}$ \\ ${ }^{1}$ Department of Clinical Medicine and Surgery, University of Veterinary and Animal \\ Sciences, Lahore \\ ${ }^{2}$ Department of Animal Health, Faculty of Veterinary Sciences, Agriculture \\ University, Peshawar \\ ${ }^{3}$ Gomal College of Veterinary Sciences, Gomal University, D.I. Khan \\ ${ }^{4}$ College of Veterinary Sciences and Animal Husbandry, Abdul Wali Khan University, \\ Mardan
}

\section{A B S T R A C T}

The aim of this project was to prepare a toxoid vaccine from the prevailing pathogenic strains of Type $D$ Clostridium perfringens strains and evaluate its immune responses in rabbits, goats and sheep. $C$. perfringens were isolated from enterotoxaemia suspected sheep and goats from the endemic areas of Khyber Pakhtunkhwa Province, Pakistan during 2016. The isolates were initially identified through colony characters, Gram staining and biochemical tests. The identified isolates were quantified on blood agar and confirmed through PCR. Toxins were extracted, quantified, formalized and adjuvanted with aluminium hydroxide gel. Safety, sterility and stability of the toxoid were ascertained. Bacterin toxoid of $C$. perfringens type $\mathrm{D}$ was procured from Veterinary Research Institute Peshawar. The immunogenicity of toxoid vaccines and bacterin toxoid vaccine were studied and compared initially in rabbits and then in goats and sheep. Experimental trials were conducted on 54 healthy animals of each species and were divided into three equal groups $(\mathrm{n}=18)$. The antibody titers were evaluated with indirect haemagglutination test. The results indicated significantly higher $(\mathrm{P}<0.05)$ immune titer in animal group vaccinated with toxoid vaccine prepared from pathogenic isolates and provide best protection against challenge infection.
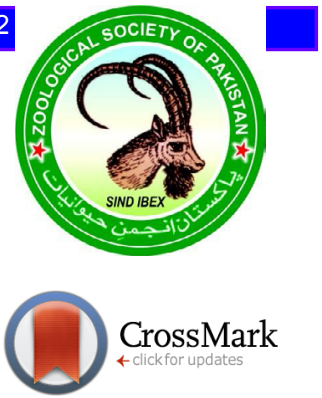

Article Information

Received 11 November 2017

Revised 13 January 2018

Accepted 13 March 2018

Available online 13 August 2018

Authors' Contribution

MAK, AZD, SBK and SGB designed the study. MAK, AZD, SBK, SGB, IH and NUK executed the experimental work and analyzed the samples. IUK, NU, KH and AUK helped in data analysis and article drafting.

Key words

Clostridium perfringens type

D, Enterotoxaemia, Indirect

haemagglutination test, Vaccine.

\section{INTRODUCTION}

C lostridium perfringens type D is the main cause of enterotoxemia (Songer, 2006), responsible for huge economic losses in sheep and goats farming globally due to high fatality rates, treatment costs and decreased productivity (Nillo, 1980; Greco et al., 2005). The clostridial organisms live ormally in gastrointestinal tract (GIT) of sheep and goats and other wild ruminants (McClane et al., 2006), but the intensity of occurrence is low. Normally these organisms produce toxins in minute quantity which is expelled from the body through normal peristaltic movement or circulating antibodies C. perfringens type $\mathrm{D}$ is also responsible for producing epsilon toxin that affects various systems of body in small ruminants. Sudden change in feeding or environmental factors may alter the internal environmental conditions of GIT where $C$. perfringens type D may rapidly multiply

\footnotetext{
Corresponding author: ikramulhaq821@gmail.com 0030-9923/2018/0005-1857 \$ 9.00/0

Copyright 2018 Zoological Society of Pakistan
}

and produce a huge amount of epsilon toxin resulting in production of disease (Nillo, 1986; Smith and Sherman, 1994). There is a big difference in pathaophysiological mechanism of enterotoxemia in sheep and goat (Blackwell and Butler, 1992). Clinically, enterotoxemia is characterized by sudden onset of death in sheep, while in goats enterotoxemia is reported to be of acute and chronic forms (Fernandez and Uzal, 2003). On postmortem examination, neurological and respiratory lesions are mainly reported in sheep whereas in goats, mainly intestinal lesions are seen (Radad and Khalil, 2011). Among different infectious diseases of small ruminants, enterotoxaemia has been reported to be the most horrifying disease. Reported incidence rate of enterotoxemia in small ruminants is $2-8 \%$, while the case fatality rate may reach $100 \%$ (Radostits, 2006). A number of factors including improper vaccination schedule or low-quality vaccine, low hygienic condition, no colostrum fed, fatty animals and low quality of feeding and watering management (Veschi et al., 2006; Khan et al., 2017) may cause the outbreaks of enterotoxaemia. To control this malady, it is necessary to provide quality vaccination and proper feeding 
management (Metre, 2010). Clostridium perfringens is a gram positive, anaerobic rod shaped bacteria belonging to genus Clostridium and is responsible for production of terminal spores (Hughes et al., 2007). C. perfringens has been divided into five groups (A-E) based on toxin types such as alpha, beta, epsilon and iota (Sayeed et al., 2005). Among different types of toxins of C. perfringens type $\mathrm{D}$, epsilon toxin is the most lethal bacterial toxin for small ruminants especially for sheep (Souza et al., 2010). The very short clinical course of this disease makes therapeutic interventions challenging and often impossible. Thus, the ideal method of control is vaccination (Chandran et al., 2010; Dela-Rosa et al., 1997; Uzal, 1997; Uzal and Kelly, 1999; Bernath et al., 2004). Toxoid vaccines are widely available commercially and have been used extensively over the past decades for use in domesticated sheep and goats. The vaccines are prepared by toxoiding C. perfringens culture filtrate, and are likely to contain a range of proteins in addition to the toxoid. The vaccines are often given with an aluminum hydroxide adjuvant to improve efficacy (Uzal and Kelly, 1999).

In Pakistan, there is a huge goat (70.3 millions) and sheep (29.8 Million) population (GoP, 2010). To minimize the losses in these animal population of small ruminants proper immunization is required to improve the health status of these animals. This project was designed to develop an effective vaccine to control future losses from C. perfringens type $\mathrm{D}$ in small ruminants.

\section{MATERIALS AND METHODS}

The study protocol was approved by the Animal Ethical Committee (Reference No. 5121, dated 09.03.2016).

\section{Bacterial cultures}

Pathogenic isolates of $C$. perfringens type D were obtained from intestinal samples taken from enterotoxaemia suspected dead sheep and goats from district Mardan of Khyber Pakhtunkhwa province, Pakistan. The samples were cultured on TCA media (HiMedia Laboratories Pvt. Ltd., India) in anaerobic condition at $37^{\circ} \mathrm{C}$ for $24 \mathrm{~h}$. The isolates were initially identified by colony morphology, Gram staining and biochemical tests kit (remel RapID ANA II system test kit Lenexa, USA). Pathogenic strains of C. perfringens were identified having more than 104$107 \mathrm{CFU} / \mathrm{g}$ colony count on blood agar (Kalender et al. 2005). C. perfringens type $\mathrm{D}$ isolates were confirmed by PCR using genomic DNA isolated from the pathogenic strains, cpa and etx specific primers

F- 5-TGC TAA TGTTAC TGC CGT TGA TAG-3; R- 5-TGC TAA TGT TAC TGC CGT TGA TAG-3 and
F-5-ATT AAA ATC ACA ATC ATT CAC TTG-3; R-5-CTT GTG AAG GGA CAT TAT GAG TAA-3 (Khan et al., 2017).

\section{Extraction and quantification of toxin}

Selected strain of $C$. perfringens type D was grown on Robertson's Cooked Meat medium anaerobically for $24 \mathrm{~h}$. The supernatant of the liquid culture was recovered through centrifugation in temperature controlled centrifugation machine for $10 \mathrm{~min}$ at $8000 \mathrm{rpm}$ and stored at $4^{\circ} \mathrm{C}$ (Tahir et al., 2013).

For quantification of toxin the extracted toxin was serially diluted tenfold using phosphate buffered saline (pH 7.3). The dilutions so achieved were 1:10, 1:20, 1:40, $1: 80,1: 160,1: 320,1: 640,1: 1280,1: 2560$ and $1: 5120.0 .5$ $\mathrm{ml}$ of the each diluted toxin was given intraperitoneally to a group of five rabbits. Rabbits were observed for mortality for 24-72 $\mathrm{h}$. The titers were calculated through Reed and Muench (1938) method and expressed as $\mathrm{LD}_{50}$ units $/ \mathrm{ml}$.

\section{Toxoid preparation}

C. perfringens type $\mathrm{D}$ was cultured in $5000 \mathrm{~mL}$ capacity flask in Robertson's Cooked Meat broth. The flasks were sealed with liquid paraffin and incubated at $37^{\circ} \mathrm{C}$ for $24 \mathrm{~h}$. The growth in flasks was tested for purity. Purified (0.1\%) trypsin (Sigma USA) was added to the flask containing type D culture. Formalin $(0.4 \%)$ was added to the flask having $C$. perfringens type $\mathrm{D}$ and was stored at room temperature for 14 days. Inactivated toxoids were adjuvanted with equal volume of aluminum hydroxide gel and were preserved in sterile vials at $4^{\circ} \mathrm{C}$.

\section{Safety, sterility and stability testing}

For safety, inactivation of toxin was tested by injecting $2 \mathrm{~mL}$ of toxoid intraperitoneally to 3 healthy rabbits. Inactivation of the toxin was confirmed with no mortality or morbidity for $24-72 \mathrm{~h}$ of the inoculation. For sterility testing toxoids were inoculated on different media i.e. nutrient agar, nutrient broth, Tarrozi and Sabouraud's agar culture media to check the presence of any contamination. Stability of the toxoid was tested after keeping the toxoids at different temperatures i.e. 25,35 and $45^{\circ} \mathrm{C}$ for 45 days (Raana, 2007).

\section{Preparation of antibodies}

C. perfringens culture was centrifuged at 2,000 rpm for $30 \mathrm{~min}$ at $4{ }^{\circ} \mathrm{C}$. The sediment was washed with phosphate buffer saline (0.15 molar, $\mathrm{pH}$ 7.2). Bacterial suspension was sonicated (Ultrasonic Homogenizer (MODEL 300VT (BioLogics, Inc. Manassas, Virginia 20109, United States of America) twice for $5 \mathrm{~min}$ at $20 \mathrm{kHz}$ and $105 \mathrm{~W}$, for 
sensitization of human $\mathrm{RBCs}$ of blood group $\mathrm{O}$ for indirect haemagglutination test (IHA). Gluteraldehyde at $1 \%$ was mixed with sensitized human RBCs of blood group $\mathrm{O}$ (Tahir et al., 2013).

\section{Measuring antibody titer}

For measuring antibodies titer the collected serum was heated to $56^{\circ} \mathrm{C}$ for $30 \mathrm{~min}$ to eliminate any nonspecific protein. $50 \mu \mathrm{L}$ of normal saline was added into the first well of 96 well U-bottom titter micro plates (Flow Labs, UK). Serum sample $(50 \mu \mathrm{L})$ was added into the 1 st well. Two fold dilutions were made by removing 50 $\mu \mathrm{L}$ from first well and added to second well and mixed well. Similarly, two fold dilutions were made until $11^{\text {th }}$ well. From $11^{\text {th }}$ well, $50 \mu \mathrm{L}$ was removed and discarded. The last well was kept negative control. $50 \mu \mathrm{L}$ of $1 \%$ gluteraldehyde fixed sensitized human RBCs of blood group $\mathrm{O}$ were added in all wells. The plate was incubated for $2 \mathrm{~h}$ at room temperature with number of times gentle tapping in order to ensure even suspension of RBCs. Haemagglutination was noted at every well bottom. The end point dilution having agglutination was reciprocal of dilution to be taken as antibody titer. Antibody titer was calculated by noticing the agglutination well number and comparing in the standard table. Geometric mean titer was calculated by taking geometric mean of antibody titers (Tahir et al. 2013).

\section{Efficacy testing}

Efficacy of toxoid was testing in rabbits, sheep and goats. For evaluation C. perfringens type D toxoids, fifty four homogenous healthy rabbits were used for immunogenicity trial, divided into three groups (A, B and C )each of 18 rabbits. Animals of group A were inoculated with $1 \mathrm{ml}$ of aluminum hydroxide gel adjuvanted $\mathrm{C}$. perfringens type D conventional toxoid (CPCT), Group B was kept as positive control by inoculating $\mathrm{C}$. perfringens type D bacterin toxoid (CPBT) of the commercially available enterotoxemia vaccine, prepared in Veterinary Research Institute (VRI) Peshawar, Pakistan while Group $\mathrm{C}$ was kept as negative control. The blood was collected on days $0,7,14$ and 28 of the vaccination for determination of immune titer. Immunized rabbits were challenged with ten times the dose of potent $\mathrm{LD}_{50}$ on day 28. The rabbits were observed for three days for any mortality. Protection percentage was calculated upon number of rabbits surviving in each group. Vaccines provoking highest antibody titers were regarded as better than the other.

For evaluation of $C$. perfringens type D toxoids in goats and sheep, thirty six healthy goats were divided into three groups (A, B and C) each of 18 goats. Animals of group A were inoculated with $1 \mathrm{ml}$ of aluminum hydroxide gel adjuvanted $C$. perfringens type $\mathrm{D}$ conventional toxoid (CPCT), Group B was kept as positive control by inoculating $C$. perfringens type D bacterin toxoid (CPBT) of the commercially available enterotoxemia vaccine, prepared in Veterinary Research Institute (VRI) Peshawar, Pakistan while Group C was kept as negative control. The blood was collected on days $0,7,14$ and 28 of the vaccination for determination of immune titer. A protocol with similar specification was adopted for evaluation the immune titer in healthy sheep against $C$. perfringens type D.

\section{Statistical analysis}

For statistical design the means of antibody titers among different groups in vaccine therapy experiment was analyzed by one way ANOVA at the level of $95 \%$ confidence interval $(\mathrm{P}<0.05)$ using SPSS 21 version of computer statistical program.

\section{RESULTS AND DISCUSSION}

Table I shows the comparison of antibody titers of rabbits, sheep and goats. In rabbits, CPCT vaccine was found with significantly higher immune titer throughout the trial following which were CPBT and unvaccinated (UV) groups. The maximum Geometric mean titer in CPCT was found to be 436.0 on $28^{\text {th }}$ day and CPBT indicated 226.67 while -ve control indicated baseline antibody titer on $28^{\text {th }}$ day post vaccination. The rabbits of both groups vaccinated with CPCT and CPBT were evaluated for protection $\%$ on $28^{\text {th }}$ day post accination. Groups of rabbits received CPCT exhibited 100\% protection from the ten times higher dose of potent $\mathrm{LD}_{50}$ challenge while protection percentage for groups of rabbits received CPBT was $70 \%$, served as positive control and -ve control groups indicated $20 \%$ protection percentage respectively. Antibody titer among trial groups on $28^{\text {th }}$ day was compared to check the difference of immune response produced in different vaccine groups. Trial showed significant difference $(P<0.05)$ among all the groups at $28^{\text {th }}$ days post inoculation.

In sheep the maximum geometric mean titer in CPCT was found 756.0 and CPBT indicated 326.5 on $28^{\text {th }}$ day while -ve control indicated baseline antibody titer on 28th day in sheep (Table I).

Vaccination trial in goats indicated significant difference $(p<0.05)$ among three groups on days 14, 21 and 28th post vaccination. The maximum geometric mean titer in CPCT group was found 444.67 and CPBT indicated 263.33 while the -ve control group indicated baseline antibody titer on $28^{\text {th }}$ day post vaccination against C. perfringens type $\mathrm{D}$. 
Table I.- Geometric mean titer comparisons of $C$. perfringens type $D$ vaccines in rabbits, sheep and goats.

\begin{tabular}{|c|c|c|c|}
\hline \multirow[t]{2}{*}{ Days } & \multicolumn{3}{|c|}{ Vaccine groups } \\
\hline & CPTC & CPBT & -ve control \\
\hline \multicolumn{4}{|c|}{ Rabbits } \\
\hline 0 & $1.67 \pm 3.2^{\mathrm{a}}$ & $1.67 \pm 3.2^{\mathrm{a}}$ & $1.67 \pm 3.2^{\mathrm{a}}$ \\
\hline 7 & $62.33 \pm 5.2^{\mathrm{a}}$ & $54.33 \pm 6.6^{b}$ & $2.00 \pm 3.9^{b}$ \\
\hline 14 & $184.67 \pm 15.2^{\mathrm{a}}$ & $75.0 \pm 6.2^{b}$ & $2.00 \pm 3.9^{\mathrm{c}}$ \\
\hline 21 & $311.83 \pm 50.7^{\mathrm{a}}$ & $166.0 \pm 12.1^{b}$ & $1.67 \pm 3.2^{\mathrm{c}}$ \\
\hline 28 & $436.0 \pm 86.6^{\mathrm{a}}$ & $226.67 \pm 41.3^{b}$ & $2.00 \pm 3.9^{\mathrm{c}}$ \\
\hline \multicolumn{4}{|c|}{ Sheep } \\
\hline 0 & $1.67 \pm 3.2^{\mathrm{a}}$ & $1.67 \pm 3.2^{\mathrm{a}}$ & $2.00 \pm 3.9^{\mathrm{a}}$ \\
\hline 7 & $89.0 \pm 7.8^{\mathrm{a}}$ & $70.0 \pm 6.1^{b}$ & $1.67 \pm 3.2^{\mathrm{c}}$ \\
\hline 14 & $205.17 \pm 47.2^{\mathrm{a}}$ & $109.50 \pm 9.9^{b}$ & $2.00 \pm 3.9^{\mathrm{c}}$ \\
\hline 21 & $373.33 \pm 53.3^{\mathrm{a}}$ & $184.67 \pm 15.2^{b}$ & $2.00 \pm 3.9^{c}$ \\
\hline 28 & $658.0 \pm 22.1^{\mathrm{a}}$ & $326.5 \pm 66.1^{b}$ & $1.67 \pm 3.2^{\mathrm{c}}$ \\
\hline \multicolumn{4}{|l|}{ Goats } \\
\hline 0 & $2.00 \pm 3.9^{\mathrm{a}}$ & $2.67 \pm 5.2^{\mathrm{a}}$ & $2.67 \pm 5.2^{\mathrm{a}}$ \\
\hline 7 & $64.83 \pm 7.8^{\mathrm{a}}$ & $59.50 \pm 10.1^{b}$ & $2.67 \pm 5.2^{b}$ \\
\hline 14 & $135.9 \pm 98^{\text {a }}$ & $94.17 \pm 22.5^{b}$ & $2.00 \pm 3.9^{\mathrm{c}}$ \\
\hline 21 & $369.33 \pm 30.5^{a}$ & $172.33 \pm 15.2^{b}$ & $2.67 \pm 5.2^{\mathrm{c}}$ \\
\hline 28 & $444.67 \pm 69.3^{\mathrm{a}}$ & $263.33 \pm 46.6^{b}$ & $2.67 \pm 5.2^{\mathrm{c}}$ \\
\hline
\end{tabular}

CPCT, Clostridium perfringens conventional toxoids; CPBT, Clostridium perfringens bacterin toxoids made in VRI Peshawar. Different superscripts indicate significant difference $(P<0.05)$

The results of our study indicated that toxoid vaccines made from prevalent isolates were more efficacious against enterotoxaemia as the toxoid vaccine gave higher geometric mean titer as compared to commercial bacterin toxoid vaccine. Similar findings have been shown by Shome et al. (2006), Das et al. (2012) and Greco et al. (2005). Humoral immune response was calculated through determination of the antibody titer by indirect haemagglutination in small ruminants which is similar to the study conducted by Tahir et al. (2013) in rabbits and small ruminants by IHA in their study. The use toxoid vaccines for the protection against $C$. perfringens infection in domesticated sheep and goats are widely available commercially and have been used extensively over the past decades. The vaccines are prepared by toxoiding $C$. perfringens culture filtrate, and are likely to contain a range of proteins in addition to the toxoid. The vaccines are often given with an aluminum hydroxide adjuvant to improve efficacy (Uzal and Kelly, 1999). Similarly, in our study toxoids were prepared from prevalent pathogenic strain and adjuvant with aluminum hydroxide for better protection. The toxoid adjuvanted with oil persists for longer period in body tissues and maintains an immune response for longer period of time in comparison of water based toxoid. The immunogen present in aqueous phase produce immediate immune response while immunogen present in oil phase persists for longer period and is responsible for immunity for the longer period (Sutmoller et al., 2003; Aslam et al., 2012). The short course of the disease mostly makes therapeutic interventions impossible therefore necessitate further research in the area of enterotoxaemia vaccine development focusing on the protection and duration of immunity (Aiello, 2003), to combat with the present lengthy and costlier schedule of the present vaccination strategy (Monika et al., 2011).

\section{CONCLUSION}

Conventional toxoid vaccine developed from local pathogenic isolates was found highly immunogenic, produced significantly higher $(\mathrm{P}<0.05)$ immune titer and provide best protection against challenge infection in rabbits.

\section{ACKNOWLEDGEMENT}

We are very thankful to Veterinary Research Institute, Peshawar and Department of Animal Health, The University of Agriculture, Peshawar for their technical and Lab support. The Project was funded by University of Veterinary and Animal Sciences, Lahore; Veterinary Research Institute, Peshawar and Department of Animal Health, The University of Agriculture, Peshawar, Pakistan.

Statement of conflict of interest

All authors declare no conflict of interest.

\section{REFERENCES}

Aiello, S.E., 2003. Merck veterinary manual. Merck, Whitehouse Station, New Jersey.

Aslam, A., Hussain, I., Mahmood, M.S., Khan, A. and Akhtar, M., 2012. Development and evaluation of Montanide-adjuvanted vaccines for the protection of chickens against inclusion body hepatitishydropericardium syndrome. Pakistan J. Zool., 44: 109-116.

Bernath, S., Fabian, K., Kadar, I., Szita, G. and Barna, T., 2004. Optimum time interval between the first vaccination and the booster of sheep for Clostridium perfringens type D. Acta Vet. Brno, 73: 473-475. https://doi.org/10.2754/avb200473040473

Blackwell, T.E. and Butler, D.G., 1992. Clinical signs treatment and postmortem lesions in dairy goats 
with enterotoxemia: 13 cases (1979-1982). J. Am. Vet. med. Assoc., 200: 214-217.

Chandran, D., Naidu, S.S., Sugumar, P., Rani, G.S., Vijayan, S.P. and Mathur, D., 2010. Development of a recombinant epsilon toxoid vaccine against enterotoxemia and its use as a combination vaccine with live attenuated sheep pox virus against enterotoxemia and sheep pox. Clin. Vaccine Immunol., 17: 1013-1016. https://doi.org/10.1128/ CVI.00013-10

Das, A., Mazumder, Y., Dutta, B.K., Shome, B.R., Bujarbaruah, K.M. and Kumar, R., 2012. Molecular typing of Clostridium perfringens isolated from diarrhoeic cattle. J. Anim. Sci. Adv., 2: 226-229.

Dela-Rosa C., Hogue, D.E. and Thonney, M.L., 1997. Vaccination schedules to raise antibody concentrations against epsilon-toxin of Clostridium perfringens in ewes and their triplet lambs. J. Anim. Sci., 75: 2328-2334. https://doi. org/10.2527/1997.7592328x

Fernandez, M.E. and Uzal, F.A., 2003. The early effects of Clostridium perfringens type D epsilon toxin in ligated intestinal loops of goat and sheep. Vet. Res. Commun., 27: 231-241. https://doi. org/10.1023/A:1023348708599

Greco, G., Madio, A., Buonavoglia, D., Totaro, M., Corrente, M., Martella, V. and Buonavoglia, C., 2005. Clostridium perfringens toxin-types in lambs and kids affected with gastroenteric pathologies in Italy. Vet. J., 170: 346-350. https:// doi.org/10.1016/j.tvj1.2004.08.001

Hughes, M.L., Poon, R., Adams, V., Sayeed, S., Saputo, J. and Uzal, F.A., 2007. Epsilon toxin plasmids of Clostridium perfringens type D are conjugative. J. Bact., 189: 7531-7538. https://doi.org/10.1128/ JB.00767-07

Kalender, H., Ertas, H.B., Cetinkaya, B., Muz, A., Arslan, N. and Kilic, A., 2005. Typing of isolates of Clostridium Perfringens from healthy and diseased sheep by multiplex PCR. Vet. Med. Czech, 50: 141148.

Khan, M.A., Durrani, A.Z., Khan, S.B., Khan, M.A., Sheikh, A.A. and Khan, N.U., 2017. Association between bacterial strain type and host biomarkers in Clostridium perfringens infected goats. Microb. Pathog., 112: 254-258. https://doi.org/10.1016/j. micpath.2017.09.059

GoP, 2010. Livestock census. Statistic Division, Gulberg, Lahore, Government of Pakistan.

Lobato, F.C.F., Lima, C.G.R.D., Assis, R.A., Pires, P.S., Silva, R.O.S. and Salvarani, F.M., 2010.
Potency against enterotoxemia of a recombinant Clostridium perfringens type D epsilon toxoid in ruminants. Vaccine, 28: 6125-6127. https://doi. org/10.1016/j.vaccine.2010.07.046

McClane, B.A., Uzal, F.A., Miyakawa, M.F., Lyerly, D. and Wilkins, T., 2006. The Enterotoxic Clostridia. In: The prokaryotes, Vol. 4 (eds. M. Dworkin, S. Falkow, E. Rosenburg, K.H. Schleifer and E. Stackebrandt). Springer-Verlag, New York, pp. 698-752. https://doi.org/10.1007/0-387-30744-

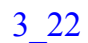

Metre, D.V., 2010. Enterotoxemia (overeating disease) of sheep and goats. Colorado State University, Colorado, USA. Extension article No. 8.018.

Monika, B., Savva, C.G., Fernandes da Costa, S.P., Naylor, C.E., Basak, A.K. and Titball, R.W., 2011. Molecular basis of toxicity of Clostridium perfringens epsilon toxin. FEBSJ., 278: 4589-4601. https://doi.org/10.1111/j.1742-4658.2011.08140.x

Nillo, L., 1980. Clostridium perfringens in animal disease: A review of current knowledge. Can. Vet. J., 21: 141-148.

Nillo, L., 1986. Experimental production of hemorrhagic enterotoxemia by Clostridium perfringens type C in maturing lambs. Can. J. Vet. Res., 50: 32-35.

Raana, W., 2007. Isolation and characterization of Clostridium perfringens from domestic animals and man in Punjab. Ph. D. thesis, Department of Microbiology. University of Veterinary and Animal Sciences, Lahore, Pakistan.

Radad, K. and Khalil, S., 2011. Coccidiosis, paratuberculosis and enterotoxaemia in Saudi goats. Brazil. J. Vet. Pathol., 4: 219-224.

Radostits, O.M., 2006. Veterinary medicine: A textbook of the diseases of cattle, sheep, goat, pig and horses, $10^{\text {th }}$ ed. Saunders Publishers, Oxford, UK.

Reed, R.H. and Muench, H., 1938. A single method of estimating fifty percent end points. Am. J. Hyg., 27: 493-497.

Sayeed, S., Fernandez-Miyakawa, M.E., Fisher, D.J., Adams, V., Poon, R. and Rood, J.I., 2005. Epsilon toxin is required for most Clostridium perfringens type D vegetative culture supernatants to cause lethality in the mouse intravenous injection model. Infect. Immunol., 73: 7413-7421. https://doi. org/10.1128/IAI.73.11.7413-7421.2005

Shome, B.R., Songer, J.G., Shakuntala, I., Shome, R., Kumar, A. and Chakraborty, S., 2006. Atypical blackleg caused by Clostridium perfringens Type A in cattle in Manipur, India. Ind. J. Anim. Sci., 76: 353-357. 
Smith, M.C. and Sherman, D.M., 1994. Enterotoxemia. In: Goat medicine (eds. M.C. Smith and D.M. Sherman). Lea and Febiger, Pennsylvania, USA, pp. 289-305.

Songer, J.G., 2006. Bovine enteritis and enterotoxemia. In: Genus Clostridium: Clostridiain medical, veterinary and food microbiology: Diagnosis and typing (eds. J. Mainil, C. Duch-esnes, P.E. Granum, M.G. Menozzi, M. Peck, S. Pelkonen, M. Popoff, E. Stackebrandt and R. Titball). Belgium, pp. 4380

Souza, A.M., Reis, J.K., Assis, R.A., Horta, C.C., Siqueira, F.F. and Facchin, S., 2010. Molecular cloning and expression of epsilon toxin from Clostridium perfringens type D and tests of animal immunization. Genet. Mol. Res., 9: 266-276. https://doi.org/10.4238/vol9-1gmr711

Sutmoller, P., Barteling, S.S., Olascoaga, R.C. and Sumption, K.J., 2003. Control and eradication of foot-and-mouth disease. Virus Res., 91: 101-144. https://doi.org/10.1016/S0168-1702(02)00262-9

Tahir, M.F., Mahmood, M.S. and Hussain, I., 2013. Preparation and comparative evaluation of different adjuvanted toxoid vaccines against enterotoxaemia. Pak. J. agric. Sci., 50: 293-297.

Uzal, F.A., 1997. Studies on enterotoxaemia in goats. Thesis, Division of Veterinary Pathobiology, School of Veterinary Science, University of Queensland, Australia, pp. 164.

Uzal, F.A. and Kelly, W.R., 1999. Serum antibody response to a Clostridium perfringens epsilon toxoid vaccine in goats. Anaerobe, 5: 287-289. https://doi.org/10.1006/anae.1999.0292

Veschi, J.L.A., Dutra, I.S., Fernandez-Miyakawa, M.E., Perri, S.H.V. and Uzal, F.A., 2006. Immunoprophylactic strategies against enterotoxemia caused by Clostridium perfringens type D in goats. Pesq. Vet. Bras., 26: 51-54. https:// doi.org/10.1590/S0100-736X2006000100011 